\title{
Effect of Solid Particles on Gas Holdup in a Slurry Bubble Column
}

\author{
Mohammed W. Abdulrahman \\ Rochester Institute of Technology \\ Dubai, UAE \\ mwacad@rit.edu
}

\begin{abstract}
A slurry bubble column SBC is a vertical cylindrical column that consists of a solid and liquid slurry and a gas that is injected from the bottom. The study of gas holdup plays an important role in the scale up analysis of a SBC from the perspective of hydrodynamics. In SBCs, the volumetric solid concentration greatly affects the hydrodynamics. Solid particles concentration in the liquid phase changes the slurry physical properties namely increase the density, and the dynamic viscosity. In this paper, the impact of solid particles concentration on overall gas holdup is studied by using computational fluid dynamics (CFD) simulations for a heliumwater-alumina slurry bubble column, where helium gas is injected at $90^{\circ} \mathrm{C}$ through a slurry of water liquid and alumina solid particles at $22^{\circ} \mathrm{C}$. It is assumed that the slurry inside the slurry bubble column is perfectly mixed, and the approaches used to model the slurry bubble column by CFD are 2D plane. In this paper, it was found that the overall gas holdup decreases by increasing the solid particle concentration at any specific superficial gas velocity and static liquid height. The CFD simulation results of the effect of solid particles concentration on gas holdup were compared with previous experimental results of helium-water-alumina SBCs for three different solid concentrations of $0 \%, 5 \%$, and $10 \%$. The results of the CFD simulations showed good agreement with the experimental results, which shows that the simulations correctly predicted the experimental effects of the solid concentrations on gas holdup.
\end{abstract}

Keywords: Slurry bubble column reactors; CFD; Gas holdup; Hydrodynamics; Solid Concentration

\section{Introduction}

A slurry bubble column reactor is a multiphase reactor. It mainly consist of a slurry phase and a gas phase, where the slurry phase consists of solid and liquid. The gas phase is fed into the column from the bottom in the form of bubbles by using a sparger. The gas bubbles move upward throughout the column to be in direct contact with the slurry and create a turbulent stream. Then the gas escape from at the top of the column.

The presence of solid particles in the liquid to create a slurry, leads to changes in the physical properties of the slurry, such as increasing the density, and the dynamic viscosity. Because of the increase in the dynamic viscosity of the slurry phase, the gas holdup will decrease with solid concentration. This will enhance the creation of large gas bubbles which will increase the bubble rise velocity and will reduce the residence time of the bubbles in the reactor.

In slurry bubble columns, there are various studies that have investigated the influence of solids concentration on gas holdup [1-3]. When adding solids to the liquid, the 'pseudo-viscosity' of the liquid phase will increase and the interface will stabilize. Hence, the coalescence rate is increased and the breakup rate is reduced, resulting in an early appearance of large bubbles. Mena et al. [4] have investigated the influence of solids concentration on flow regime stability in a $0.14 \mathrm{~m}$ diameter column using air, distilled water, and calcium alginate beads. They have found that transition velocity increases with solids loading up to $3 \%$ vol. and then decreases at higher solids loading (> $3 \%$ vol.). A possible explanation for such dual effect behavior is based on bubble-particle interaction. The stabilizing and then destabilizing effects with an addition of solids appear qualitatively similar to those observed by Ruzicka et al. [5], who have increased viscosity by an addition of glycerol.

Vandu and Krishna [6] and Shaikh and Al-Dahhan [7] have observed a decrease in transition velocity when increasing solids concentration, without the maximum as observed by Mena et al. [4]. However, it is worth mentioning that these authors have not studied low solids loading in the range between 0-3\% vol. where Mena et al. [4] observed a maximum in transition velocity. In addition, the particle size used by Mena et al. [4] was larger $(2.1 \mathrm{~mm})$ than the one commonly employed in slurry bubble columns and also used by these authors $(50-150 \mu \mathrm{m})$.

Jamialahmadi and Muller-Steinhagen [8] have shown that the change in gas holdup in the air-water system by adding solids, depends on the kind of the solids. It has been found that gas holdup will decrease by adding non-wettable solids, 
while gas holdup will increase when adding wettable solids. Hence, the effect of solids on transition velocity needs to be studied in terms of the nature of the solids.

There are several studies that have investigated the impact of solid concentration and size on $\alpha_{g}$. Most of these studies have found that gas holdup decreases by increasing solids concentration [9, 1]. Sada et al. [10] have found that the effect of solids concentration is insignificant when the solids loading is less than 5 vol. \%. On the contrary, Kara et al. [11] have reported a significant effect of solids concentration on gas holdup at low solids loading. Kato et al. [12] have found that solid concentrations affect gas holdup significantly when the gas velocities are higher than 10-20 cm/s [9]. de Swart et al [13] have studied the gas holdup of air in a paraffin oil liquid and glass beads solid particles at atmospheric conditions. Their solid concentration was varied up to 20 vol. \%. They have found that the holdup of the large gas bubbles was independent on the slurry concentration. This result was confirmed by Krishna et al. [14] who used the same three phase system with solid concentration as high as 36 vol.\% while using three different column diameters. Abdulrahman [15-19] has performed experimental studies in hydrodynamics and heat transfer of a helium-water-alumina SBC. He has found new empirical equations for the gas holdup and volumetric heat transfer coefficient [15, 17-19].

The knowledge of the slurry viscosity is therefore important for estimating the gas holdup in SBCRs. Table 1 summarizes some available correlations for predicting the slurry viscosity [1]. Figure 1 shows the slurry viscosity obtained from equations in Table 1 as a function of solid volumetric concentration. In this figure it can be seen that most correlations are independent of the nature of the solid particles. The correlation proposed by Riquarts [20], however, takes into account the density of the particles.

Table 1: Available correlations for predicting slurry viscosity [1].

\begin{tabular}{|l|l|}
\hline \multicolumn{1}{|c|}{ Author } & \multicolumn{1}{c|}{ Correlation } \\
\hline Saxena and Chen [21] & $\mu_{S l}=\mu_{l}\left(1+4.5 C_{S}\right)$ \\
\hline Thomas [22] & $\mu_{s l}=\mu_{l}\left(1+2.5 C_{S}+10.05{C_{S}}^{2}+0.00273 e^{16.6 C_{s}}\right)$ \\
\hline Guth and Simba [23] & $\mu_{s l}=\mu_{l}\left(1+2.5 C_{S}+14.1 C_{S}{ }^{2}\right)$ \\
\hline Barnea and Mizrahi [24] & $\mu_{s l}=\mu_{l} \exp \left(\frac{\frac{5}{3} C_{s}}{1-C_{s}}\right)$ \\
\hline Roscoe [25] & $\mu_{S l}=\mu_{l}\left(1-C_{S}\right)^{-2.5}$ \\
\hline Riquarts [20] & $\mu_{s l}=\mu_{l}\left(1+\frac{\rho_{S}+\rho_{l}}{\rho_{l}} C_{s}\right)\left(1-C_{s}\right)^{-2.59}$ \\
\hline Vand [26] & $\mu_{s l}=\mu_{l} \exp \left(\frac{2.5 C_{s}}{1-0.609 C_{s}}\right)$ \\
\hline
\end{tabular}

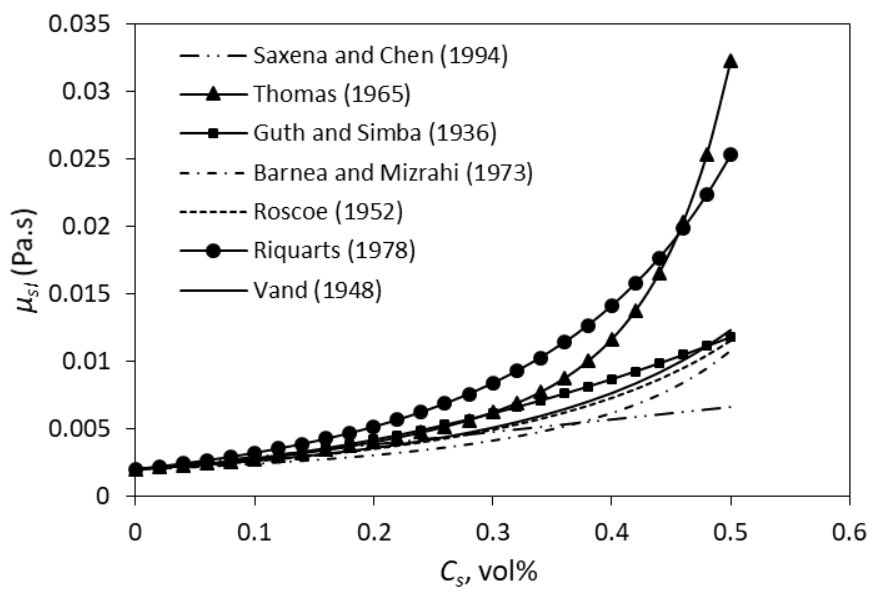

Fig. 1: Correlations for predicting slurry viscosity in molten salt $\mathrm{CuCl}$. 
There are several studies that have investigated CFD simulation modelling in multiphase flow [27-32]. Law et al. [33] have studied the average gas holdup by using 2-D and 3-D models for a bubble column. They have concluded that the results of the average gas holdup in both 3-D and 2-D simulations can be comparable if their resolutions are comparable. Rampure et al. [34] have measured experimentally and numerically (CFD) the gas holdup for two and three phase systems. They have showed that the CFD results over predicted the experimental results [35]. Krishna et al. have studied experimentally and numerically (CFD) the effect of the column diameter on gas holdup, and showed good agreement of both results [2]. Abdulrahman [36, 37] has studied the heat transfer in a SBC by using 2-dimensional CFD analyses. He has investigated the effect of solid particles concentration on the volumetric heat transfer coefficient and the temperature distribution of the SBC. The results of the CFD simulation have correctly predicted the experimental results of the solid concentration effect on heat transfer. In this paper, 2-dimensional CFD simulations are performed to predict the effect of the solid particle concentration on gas holdup by using ANSYS FLUENT software.

\section{CFD Simulations of the Multiphase Flow}

Table 2 shows the equations used in the CFD analysis of this paper, and Table 3 summarizes the setup of the BC problem in ANSYS FLUENT.

Table 2: Details of equations used in the CFD simulations.

\begin{tabular}{|c|c|c|c|}
\hline $\begin{array}{l}\text { Description } \\
\text { [reference] }\end{array}$ & Phase & Equation & Notes \\
\hline \multirow{2}{*}{$\begin{array}{c}\text { Volume equation } \\
{[38]}\end{array}$} & Gas & $V_{g}=\int_{V} \alpha_{g} d V$ & \multirow{2}{*}{$\begin{array}{l}\text { Equations of } V_{g} \text { and } V_{l} \text { must } \\
\text { satisfy: } \alpha_{g}+\alpha_{l}=1\end{array}$} \\
\hline & Slurry & $V_{s l}=\int_{V} \alpha_{s l} d V$ & \\
\hline \multirow{2}{*}{$\begin{array}{c}\text { Continuity equation } \\
\text { in 2D Cartesian } \\
\text { coordinates }(x, y) \\
{[39]}\end{array}$} & Gas & $\frac{\partial v_{x, g}}{\partial x}+\frac{\partial v_{y, g}}{\partial y}=0$ & \\
\hline & Slurry & $\frac{\partial v_{x, s l}}{\partial x}+\frac{\partial v_{y, s l}}{\partial y}=0$ & \\
\hline \multirow{4}{*}{$\begin{array}{l}\text { Momentum equation } \\
\text { in 2D Cartesian } \\
\text { coordinates [40] }\end{array}$} & $\begin{array}{c}\text { Gas } \\
\underline{x-} \\
\underline{\text { direction }} \\
\end{array}$ & $\begin{array}{c}\rho_{g} \alpha_{g}\left(\frac{\partial v_{x}}{\partial t}+v_{x} \frac{\partial v_{x}}{\partial x}+v_{y} \frac{\partial v_{x}}{\partial y}\right)=-\alpha_{g} \frac{\partial P}{\partial x}+ \\
\alpha_{g} \frac{\mu_{g, e f f}}{3} \frac{\partial(\nabla . V)}{\partial x}+\mu_{g, e f f} \alpha_{g}\left[\frac{\partial^{2} v_{x}}{\partial x^{2}}+\frac{\partial^{2} v_{x}}{\partial y^{2}}\right]+ \\
\rho_{g} \alpha_{g} g_{x}+M_{i, g, x}\end{array}$ & \\
\hline & $\begin{array}{c}\text { Gas } \\
y- \\
\text { direction }\end{array}$ & $\begin{array}{c}\rho_{g} \alpha_{g}\left(\frac{\partial v_{y}}{\partial t}+v_{x} \frac{\partial v_{y}}{\partial x}+v_{y} \frac{\partial v_{y}}{\partial y}\right)=-\alpha_{g} \frac{\partial P}{\partial y}+ \\
\alpha_{g} \frac{\mu_{g, e f f}}{3} \frac{\partial(\nabla . V)}{\partial y}+\mu_{g, \text { eff }} \alpha_{g}\left[\frac{\partial^{2} v_{y}}{\partial x^{2}}+\frac{\partial^{2} v_{y}}{\partial y^{2}}\right]+ \\
\rho_{g} \alpha_{g} g_{y}+M_{i, g, y}\end{array}$ & \\
\hline & $\begin{array}{c}\text { Slurry } \\
\underline{x-} \\
\text { direction } \\
\end{array}$ & $\begin{array}{c}\rho_{l} \alpha_{s l}\left(\frac{\partial v_{x}}{\partial t}+v_{x} \frac{\partial v_{x}}{\partial x}+v_{y} \frac{\partial v_{x}}{\partial y}\right)=-\alpha_{s l} \frac{\partial P}{\partial x}+ \\
\alpha_{s l} \frac{\mu_{s l, e f f}}{3} \frac{\partial(\nabla . V)}{\partial x}+\mu_{s l, e f f} \alpha_{l}\left[\frac{\partial^{2} v_{x}}{\partial x^{2}}+\frac{\partial^{2} v_{x}}{\partial y^{2}}\right]+ \\
\rho_{s l} \alpha_{s l} g_{x}+M_{i, s l, x}\end{array}$ & \\
\hline & $\begin{array}{c}\text { Slurry } \\
y- \\
\text { direction } \\
\end{array}$ & $\begin{array}{c}\rho_{s l} \alpha_{s l}\left(\frac{\partial v_{y}}{\partial t}+v_{x} \frac{\partial v_{y}}{\partial x}+v_{y} \frac{\partial v_{y}}{\partial y}\right)=-\alpha_{s l} \frac{\partial P}{\partial y}+ \\
\alpha_{s l} \frac{\mu_{s l, e f f}}{3} \frac{\partial(\nabla . V)}{\partial y}+\mu_{s l, e f f} \alpha_{s l}\left[\frac{\partial^{2} v_{y}}{\partial x^{2}}+\frac{\partial^{2} v_{y}}{\partial y^{2}}\right]+ \\
\rho_{s l} \alpha_{s l} g_{y}+M_{i, s l, y}\end{array}$ & \\
\hline Effective density & Gas & $\hat{\rho}_{g}=\alpha_{g} \rho_{g}$ & \\
\hline
\end{tabular}




\begin{tabular}{|c|c|c|c|}
\hline & Slurry & $\hat{\rho}_{s l}=\alpha_{s l} \rho_{s l}$ & \\
\hline \multirow{2}{*}{$\begin{array}{l}\text { Effective dynamic } \\
\text { viscosity }[41,42]\end{array}$} & Gas & $\hat{\mu}_{g}=\frac{\rho_{g}}{\rho_{l}} \hat{\mu}_{l}$ & $\begin{array}{l}\text { The equations used for } k-\epsilon \\
\text { turbulence model }\end{array}$ \\
\hline & Slurry & $\hat{\mu}_{s l}=\mu_{l a m, s l}+\mu_{t u r, s l}+\mu_{B I T, s l}$ & \\
\hline $\begin{array}{l}\text { Total interfacial force } \\
\text { acting between the } \\
\text { phases [38] }\end{array}$ & & $M_{i, s l}=-M_{i, g}=M_{D}$ & $\begin{array}{l}\text { The equation of } M_{i, s l} \text { can be } \\
\text { obtained after neglecting the } \\
\text { lift force [18] and the virtual } \\
\text { mass force [36] }\end{array}$ \\
\hline Drag force [38] & & $M_{D}=\frac{\rho_{g} f}{6 \tau_{b}} d_{b} A_{i}\left(\boldsymbol{V}_{\boldsymbol{g}}-\boldsymbol{V}_{\boldsymbol{s l}}\right)$ & $\begin{array}{l}\text { The equation is for gas-liquid } \\
\text { system }\end{array}$ \\
\hline Interfacial area [38] & & $A_{i}=\frac{6 \alpha_{g}\left(1-\alpha_{g}\right)}{d_{h}}$ & \\
\hline $\begin{array}{c}\text { Particular relaxation } \\
\text { time [38] }\end{array}$ & & $\tau_{b}=\frac{\rho_{g} d_{b}^{2}}{18 \mu_{s l}}$ & \\
\hline Drag function [38] & & $f=\frac{C_{D} R e}{24}$ & \\
\hline $\begin{array}{c}\text { Reynolds number } \\
\text { [38] }\end{array}$ & & $R e=\frac{\rho_{s l}\left|V_{g}-V_{s l}\right| d_{b}}{\mu_{s l}}$ & $\begin{array}{l}\left|\boldsymbol{V}_{\boldsymbol{g}}-\boldsymbol{V}_{\boldsymbol{s l}}\right| \text { : slip velocity of the } \\
\text { gas and slurry phases } \\
d_{b} \text { : is recommended to be } \\
\text { Sauter-mean diameter }\end{array}$ \\
\hline $\begin{array}{l}\text { Schiller-Naumann } \\
\text { drag equation [43] }\end{array}$ & & $C_{D}= \begin{cases}\frac{24\left(1+0.15 R e_{b}^{0.687}\right)}{R e_{b}} & R e_{b} \leq 1000 \\
0.44 & R e_{b}>1000\end{cases}$ & \\
\hline
\end{tabular}

Table 3: Summary of the BC problem setup in ANSYS FLUENT.

\begin{tabular}{|c|c|c|c|}
\hline \multirow{5}{*}{ General } & Solver Type & \multicolumn{2}{|l|}{ Pressure-Based } \\
\hline & Velocity Formulation & \multicolumn{2}{|l|}{ Absolute } \\
\hline & Time & \multicolumn{2}{|l|}{ Steady } \\
\hline & Gravity & \multicolumn{2}{|l|}{ ON } \\
\hline & 2D Space & \multicolumn{2}{|l|}{ Planar } \\
\hline \multirow{3}{*}{ Models } & \multicolumn{3}{|l|}{ Multiphase-Eulerian } \\
\hline & \multicolumn{3}{|c|}{ Energy-On } \\
\hline & \multicolumn{3}{|c|}{ Viscous-Standard $k-\varepsilon$, Standard Wall Function, Dispersed } \\
\hline \multirow{2}{*}{ Materials } & \multicolumn{3}{|c|}{ Water liquid } \\
\hline & \multicolumn{3}{|c|}{ Helium gas } \\
\hline \multirow{2}{*}{ Phases } & \multicolumn{3}{|c|}{ Primary phase $=$ liquid phase } \\
\hline & \multicolumn{3}{|c|}{ Secondary Phase $=$ gas phase } \\
\hline Bubble Diameter & \multicolumn{3}{|c|}{ Sauter-mean diameter } \\
\hline \multirow{7}{*}{ Solution Methods } & \multirow{7}{*}{ Spatial Discretization } & \multicolumn{2}{|l|}{ Phase-Coupled SIMPLE } \\
\hline & & Gradient & Least Squares Cell Based \\
\hline & & Momentum & Second Order Upwind \\
\hline & & Volume Fraction & First Order Upwind \\
\hline & & Turbulent Kinetic Energy & Second Order Upwind \\
\hline & & Turbulent Dissipation Rate & Second Order Upwind \\
\hline & & Energy & Second Order Upwind \\
\hline
\end{tabular}




\begin{tabular}{|l|l|l|l|}
\hline & \multicolumn{2}{|c|}{ Interfacial Area Concentration } & Second Order Upwind \\
\hline Number of Iterations & 100,000 & & \\
\hline
\end{tabular}

In this paper, the 2D-CFD analysis of the BC is studied using the ANSYS FLUENT V.13 software. The overall diameter of the $\mathrm{BC}$ is taken to be $21.6 \mathrm{~cm}$ and height of static liquid of the $\mathrm{BC}$ is taken to have three different values (45, 55 , and $65 \mathrm{~cm}$ ). First, ANSYS WORKBENCH V.13 was implemented to draw 2D geometries of the BC and to create meshing. Quadratic mapped mesh is used for the area of the BC and a very fine mesh is used near the wall. The size of the mesh is selected so that there is no dependence of the gas holdup $\left(\alpha_{g}\right)$ on grid. Table 4 shows the grid independence study that was used to select the optimum grid distribution of the BC problem. From Table 4, it can be seen that the optimum grid is when the number of cells is 20,203 cells, because this will provide minimum relative errors of $0.43 \%$ for the values of $\alpha_{g}$, when compared with the grid of 56,341 cells. When using the grid of 56,341 cells, the memory requirement of the computer as well as the calculation time will increase significantly because the number of cells is more than twice of that of 20,203. Since the relative errors of $\alpha_{g}$ between the two grids are very small, it is preferred to use the grid of 20,203 cells and reduce the memory requirement of the computer and the calculation time. The quantity of interest that is monitored during the CFD simulation is the overall gas holdup. The convergence criteria of the simulation is to ensure that the quantity of interest reached a steady state simulation and the residual RMS error values were less than $10^{-4}$.

Table 4: Grid independence test for a helium-water BC $\left(H=65 \mathrm{~cm}, U_{g s}=0.15 \mathrm{~m} / \mathrm{s}\right)$.

\begin{tabular}{|c|c|c|c|c|}
\hline $\begin{array}{c}\text { Total } \\
\text { Cells }\end{array}$ & 3,704 & 20,203 & 34,288 & $\begin{array}{c}56,34 \\
1\end{array}$ \\
\hline$\alpha_{g}(\%)$ & 22.3 & 23 & 22.8 & 23.1 \\
\hline
\end{tabular}

\section{Results}

\subsection{Effect of solid particle concentration $\left(C_{s}\right)$ on $\alpha_{g}$}

Figures 2-5 show the plots and contours of the numerical $\alpha_{g}$ as a function of $U_{g s}$ and $C_{s}$ of helium-water-alumina $\mathrm{SBC}$ with a static liquid heights $(H)$ of 45 and $65 \mathrm{~cm}$. From these figures, it can be seen that $\alpha_{g}$ decreases by increasing $C_{s}$.

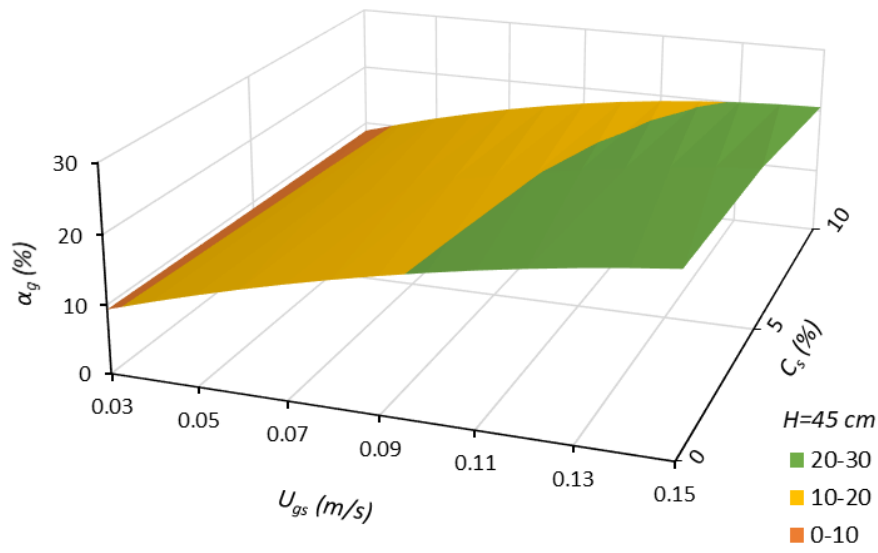

Fig. 2: Numerical $\alpha_{g}$ versus $U_{g s}$ and $C_{s}$ of helium-water-alumina SBC. 


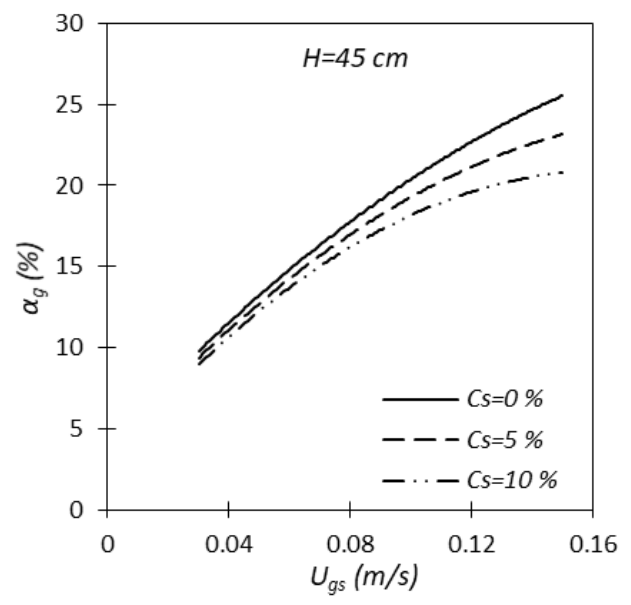

(a)

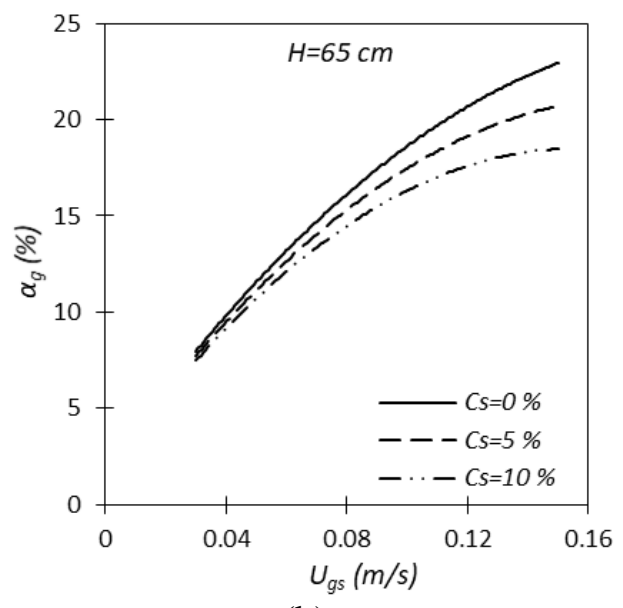

(b)

Fig. 3: Effect of $C_{s}$ on $\alpha_{g}$ versus $U_{g s}$ of helium-water-alumina $\mathrm{SBC}$ for a) $H=45 \mathrm{~cm}$, b) $H=65 \mathrm{~cm}$.

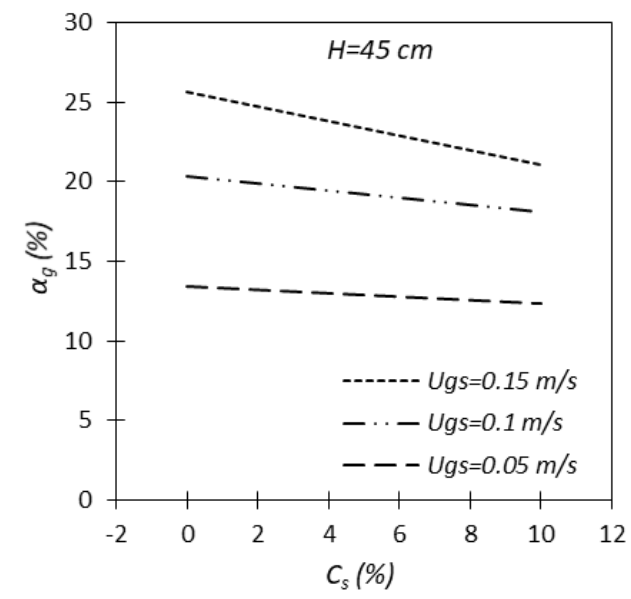

(a)

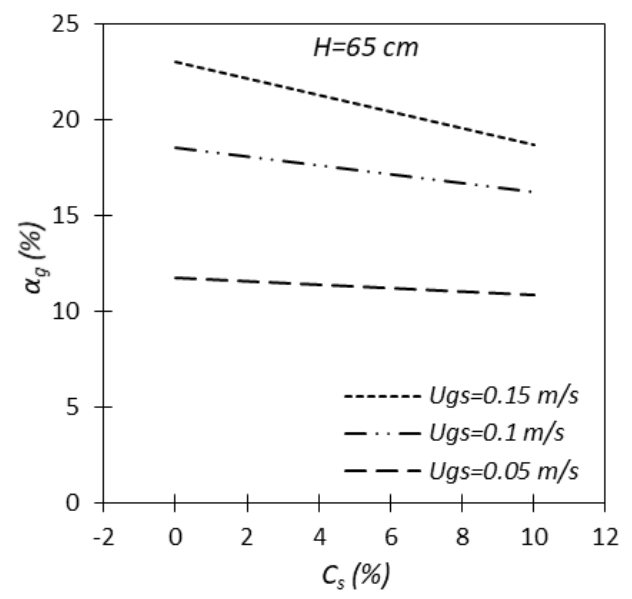

(b)

Fig. 4: Numerical $\alpha_{g}$ versus $C_{s}$ of helium-water-alumina SBC for a) $H=45 \mathrm{~cm}$, b) $H=65 \mathrm{~cm}$.
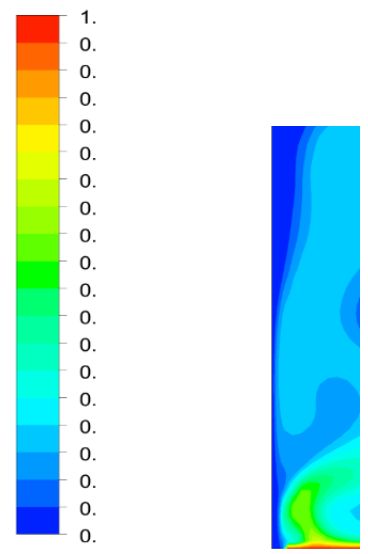

$$
C_{s}=0 \%
$$
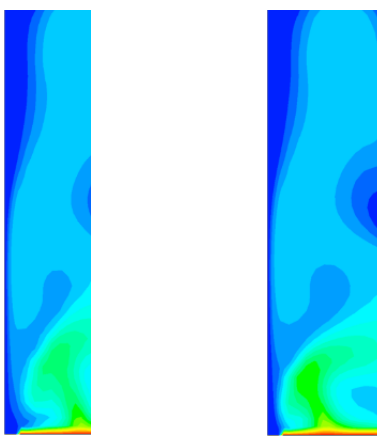

$$
C_{s}=5 \%
$$$$
C_{s}=10 \%
$$

Fig. 5: Contours of $\alpha_{g}$ of a helium-water BC with $H=65 \mathrm{~cm}, U_{g s}=0.1 \mathrm{~m} / \mathrm{s}$ and different $C_{s}$. 


\subsection{Comparison of Numerical $\alpha_{g}$ with the Experimental Data}

To validate the numerical (CFD) data of hydrodynamic studies produced in the helium-water $\mathrm{BC}$, a comparison is made with the experimental data of Abdulrahman [15-19]. Figs. 6 and 7 compare between the CFD simulations and experimental results for the effects of $C_{s}$ on $\alpha_{g}$. It is shown that the CFD results of $\alpha_{g}$ under-predict the experimental data with a maximum relative error of less than $21.7 \%$. Considering the complexity of the multi-phase flow in bubble columns, the agreement is satisfactory and encouraging. The reduction in the results of CFD models is mainly attributed to the use of a 2D-plane mesh that create lower gas flow rates when compared with the 3D mesh [44]. Fig. 7 shows that at a specific $H$, the curves of $\alpha_{g}$ versus $U_{g s}$ for different values of $C_{s}$, are not parallel to each other. This means that the rate of decrease of $\alpha_{g}$ with $C_{s}$ increases by increasing $U_{g s}$, where at low $U_{g s}$, the effect of $C_{s}$ is insignificant and it increases by increasing $U_{g s}$. The CFD model correctly predicted the experimental effects of $C_{s}$ on $\alpha_{g}$.

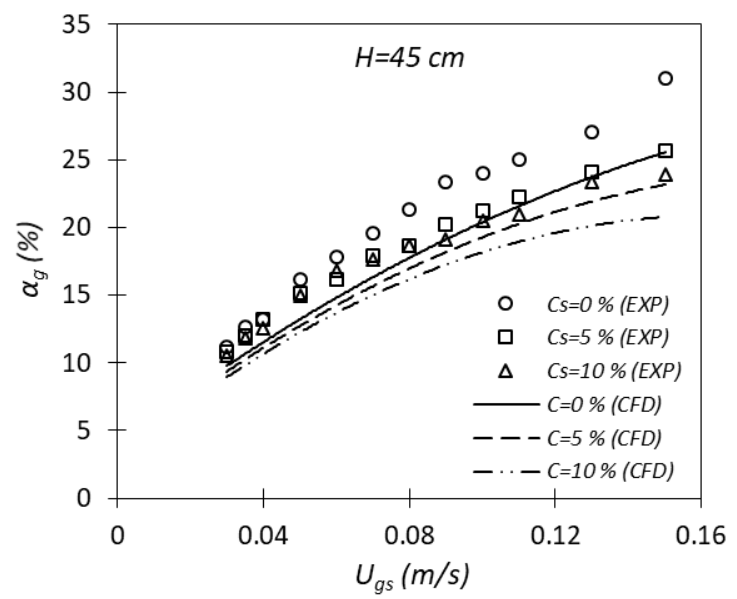

Fig. 6: Effect of $C_{s}$ on $\alpha_{g}$ versus $U_{g s}$ of helium-water BC for experimental data and CFD model.

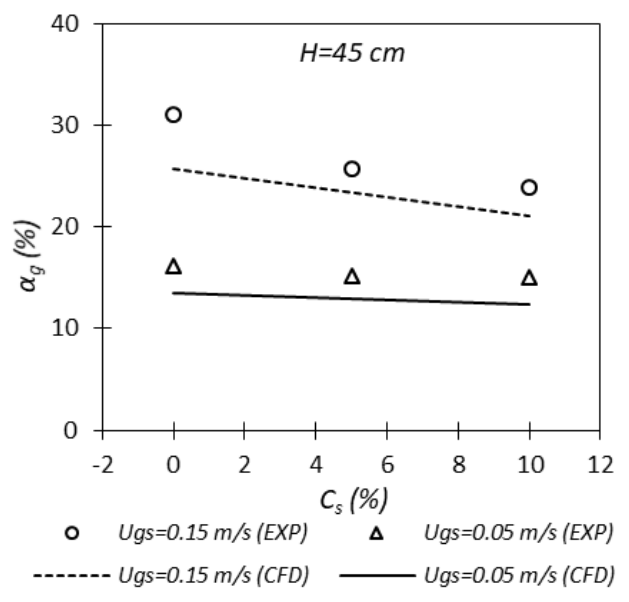

(a)

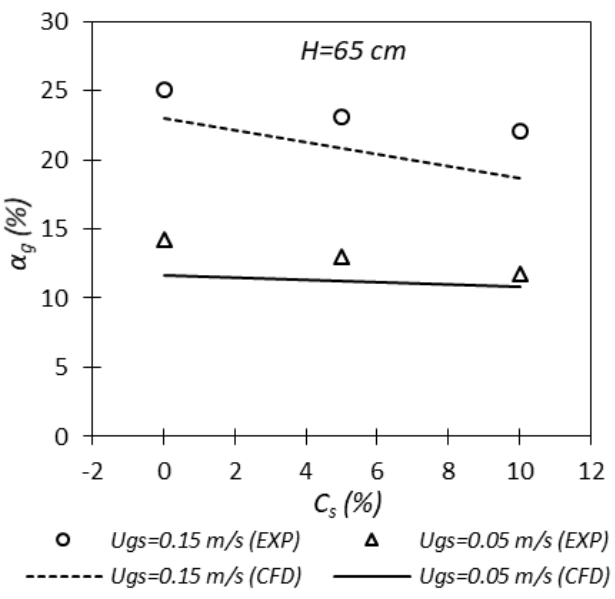

(b)

Fig. 7: Comparison between CFD and experimental $\alpha_{g}$ versus $C_{s}$ of helium-water-alumina SBC for different $U_{g s}$ and a) $H=45 \mathrm{~cm}$, b)

$$
H=65 \mathrm{~cm} \text {. }
$$




\section{Conclusion}

In this paper, the CFD simulations of helium-water-alumina SBC were created in two dimensions to find the effects of solid concentrations on gas hold-up. The results of gas holdup versus solid concentrations were compared with the experimental data and showed good agreement, which shows that the CFD simulations for the impact of solid concentration on gas holdup in SBCs are applicable.

\section{Nomenclature}

\begin{tabular}{|c|c|c|c|}
\hline Symbol & Definition & Symbol & Definition \\
\hline$A_{i}$ & Interfacial area $\left(\mathrm{m}^{2}\right)$ & $V_{g}$ & Velocity field of gas phase $(\mathrm{m} / \mathrm{s})$ \\
\hline$C_{D}$ & Drag coefficient & $V_{s l}$ & Velocity field of slurry phase $(\mathrm{m} / \mathrm{s})$ \\
\hline$C_{S}$ & Volumetric solid concentration & $\alpha_{g}$ & Gas holdup \\
\hline$d_{b}$ & Bubble diameter $(\mathrm{m})$ & $\alpha_{s l}$ & Slurry holdup \\
\hline$f$ & Drag function & $\mu_{e f f}$ & Effective dynamic viscosity (Pa.s) \\
\hline$g$ & Gravitational acceleration $\left(\mathrm{m}^{2} / \mathrm{s}\right)$ & $\mu_{g}$ & Dynamic viscosity of gas phase (Pa.s) \\
\hline$H$ & Height of static liquid (m) & $\mu_{s l}$ & Dynamic viscosity of slurry phase (Pa.s) \\
\hline$M_{D}$ & Drag force $\left(\mathrm{N} / \mathrm{m}^{3}\right)$ & $\hat{\mu}_{g}$ & Effective dynamic viscosity of gas (Pa.s) \\
\hline$M_{i}$ & Total interfacial force acting between phases $\left(\mathrm{N} / \mathrm{m}^{3}\right)$ & $\hat{\mu}_{s l}$ & $\begin{array}{l}\text { Effective dynamic viscosity of slurry } \\
\text { (Pa.s) }\end{array}$ \\
\hline$P$ & Pressure $(\mathrm{Pa})$ & $\mu_{l a m, l}$ & Molecular viscosity (Pa.s) \\
\hline$R e$ & Reynolds number & $\mu_{t u r, l}$ & Shear-induced turbulent viscosity (Pa.s) \\
\hline$U_{g s}$ & Superficial velocity of gas $(\mathrm{m} / \mathrm{s})$ & $\mu_{B I T, l}$ & $\begin{array}{l}\text { Bubble-induced turbulence viscosity } \\
\text { (Pa.s) }\end{array}$ \\
\hline$v_{x, g}$ & Velocity component in $x$-direction of gas phase $(\mathrm{m} / \mathrm{s})$ & $\rho$ & Density $\left(\mathrm{kg} / \mathrm{m}^{3}\right)$ \\
\hline$v_{x, s l}$ & $\begin{array}{l}\text { Velocity component in } x \text {-direction of slurry phase } \\
(\mathrm{m} / \mathrm{s})\end{array}$ & $\rho_{g}$ & Density of gas $\left(\mathrm{kg} / \mathrm{m}^{3}\right)$ \\
\hline$v_{y, g}$ & Velocity component in $y$-direction of gas phase $(\mathrm{m} / \mathrm{s})$ & $\rho_{s l}$ & Density of liquid $\left(\mathrm{kg} / \mathrm{m}^{3}\right)$ \\
\hline$v_{y, s l}$ & $\begin{array}{l}\text { Velocity component in } y \text {-direction of slurry phase } \\
(\mathrm{m} / \mathrm{s})\end{array}$ & $\hat{\rho}_{g}$ & Effective density of gas phase $\left(\mathrm{kg} / \mathrm{m}^{3}\right)$ \\
\hline$V_{g}$ & Volume of gas phase $\left(\mathrm{m}^{3}\right)$ & $\hat{\rho}_{s l}$ & Effective density of slurry phase $\left(\mathrm{kg} / \mathrm{m}^{3}\right)$ \\
\hline$V_{S}$ & Volume of solid phase $\left(\mathrm{m}^{3}\right)$ & $\tau_{b}$ & Particulate relaxation time $(\mathrm{s})$ \\
\hline$\hat{V}_{S l}$ & Volume of slurry $\left(\mathrm{m}^{3}\right)$ & & \\
\hline
\end{tabular}

\section{References}

[1] A. Behkish, "Hydrodynamic and mass transfer parameters in large-scale slurry bubble column reactors," Ph.D. dissertation, University of Pittsburgh, Pennsylvania, USA, 2004.

[2] R. Krishna, J. Ellenberger, and C. Maretto, "Flow regime transition in bubble columns," International Communications in Heat and Mass Transfer, vol.26, no. 4, pp. 467-475, 1999.

[3] K. Ruthiya, "Mass transfer and hydrodynamics in catalytic slurry reactors," Ph.D dissertation, Eindhoven University, the Netherlands, 2005.

[4] P. C. Mena, M. C. Ruzicka, F. A. Rocha, J. A. Teixeira, and J. Drahos, "Effect of solids on homogeneous heterogeneous flow regime transition in bubble columns," Chemical Engineering Science, vol. 60, no. 22, pp. 6013-6026, 2005. 
[5] M.C. Ruzicka, J. Zahradnik, J. Drahos, and N. H. Thomas, "Homogeneous-heterogeneous regime transition in bubble columns," Chemical Engineering Science, vol. 56, no. 15, pp. 4609-4626, 2001.

[6] C. O. Vandu, and R. Krishna, "Volumetric mass transfer coefficients in slurry bubble columns operating in churn-turbulent flow regime," Chemical Engineering and Processing, vol. 43, pp. 987-995, 2004.

[7] A. Shaikh, and M. Al-Dahhan, Hydrodynamics of slurry bubble column reactors. CREL Internal Report, 2006.

[8] M. Jamialahmadi, and H. Mueller-Steinhagen, "Effect of solid particles on gas hold-up in bubble columns," The Canadian Journal of Chemical Engineering, vol. 69, no. 1, pp. 390-393, 1991.

[9] K. Nigar, B. Fahir, and O. U. Kutlu, "Review: Bubble column reactors," Process Biochemistry, vol. 40, pp. $2263-$ 2283, 2005.

[10] E. Sada, S. Katoh, and H. Yoshil, "Performance of the gas-liquid bubble column in molten salt systems," Industrial \& Engineering Chemistry Process Design and Development, vol. 23, pp. 151-154, 1984.

[11] S. Kara, B. G. Kelkar, Y. T. Shah, and N. L. Carr, "Hydrodynamics and axial mixing in a three-phase bubble column," Industrial \& Engineering Chemistry Process Design and Development, vol. 21, pp. 584-594, 1982.

[12] Y. Kato, A. Nishiwaki, T. Kago, T. Fukuda, and S. Tanaka, "Gas holdup and overall volumetric absorption coefficient in bubble columns with suspended solid particles," Transactions of the Institution of Chemical Engineers, vol. 13, pp. 562-567, 1973.

[13] J. W. A. de Swart, R. E. Van Vliet, and R. Krishna, "Size, structure and dynamics of "large" bubbles in a twodimensional slurry bubble column," Chemical Engineering Science, vol. 51, pp. 4619-4629, 1996.

[14] R. Krishna, J. W. A. De Stewart, J. Ellenberger, G. B. Martina, and C. Maretto, "Gas holdup in slurry bubble columns: effect of column diameter and slurry concentrations," American Institute of Chemical Engineers Journal, vol. 43, pp. 311-316, 1997.

[15] M. W. Abdulrahman, "Experimental studies of gas holdup in a slurry bubble column at high gas temperature of a helium- water- alumina system," Chemical Engineering Research and Design, vol.109, pp. 486-494, 2016.

[16] M. W. Abdulrahman, "Experimental studies of the transition velocity in a slurry bubble column at high gas temperature of a helium-water-alumina system," Experimental Thermal and Fluid Science, vol. 74, pp. 404-410, 2016.

[17] M. W. Abdulrahman, "Experimental studies of direct contact heat transfer in a slurry bubble column at high gas temperature of a helium-water-alumina system," Applied Thermal Engineering, vol. 91, pp. 515-524, 2015.

[18] M. W. Abdulrahman, "Direct contact heat transfer in the thermolysis reactor of hydrogen production cu-cl cycle," US Patent 10059 586, August 28, 2018.

[19] M. W. Abdulrahman, "Analysis of the thermal hydraulics of a multiphase oxygen production reactor in the $\mathrm{Cu}-\mathrm{Cl}$ cycle,” Ph.D. dissertation, UOIT, Ontario, Canada, 2016.

[20] H. P. Riquarts, Disperse two-phase flows: Calculation principles and their application. Habilitationsschrift, TU Muenchen, 1978.

[21] S. C. Saxena, and Z. D. Chen, "Hydrodynamics and heat transfer of baffled and unbaffled slurry bubble column," Reviews in Chemical Engineering, vol. 10, no. 3-4, pp. 193-400, 1994.

[22] D. G. Thomas, "Transport characteristics of suspension: VIII. A note on viscosity of Newtonian suspensions of uniform spherical particles," Journal of Colloid Science, vol. 20, pp. 267-277, 1965.

[23] E. Guth, and H. Simba, "Viscosity of suspensions and solutions: III Viscosity of sphere suspensions," Kolloid-Z, vol. 74, pp. 266-275, 1936.

[24] E. Barnea, and J. A. Mizrahi, "Generalized approach to the fluid dynamics of particulate system. Part 1 general correlation for fluidization and sedimentation in solid multi particle systems," The Chemical Engineering Journal, vol. 5, pp. 171-189, 1973.

[25] R. Roscoe, "The viscosity of suspension of rigid spheres," British Journal of Applied Physics, vol. 3, no. 8, pp. 267-269, 1952.

[26] V. Vand, "Viscosity of solutions and suspensions. I. Theory," Journal of Physical Chemistry, vol. 52, pp. 277299, 1948. 
[27] C. Chen, and L. S. Fan, "Discrete simulation of gas-liquid bubble columns and gas-liquid-solid fluidized beds," American Institute of Chemical Engineers Journal, vol. 50, pp. 288-301, 2004.

[28] H. A. Jakobsen, B. H. Sannaes, S. Grevskott, and H. F. Svendsen, "Modelling of vertical bubble-driven flows," Industrial \& Engineering Chemistry Research, vol. 36, pp. 4052-4074, 1997.

[29] J. B. Joshi, "Computational flow modelling and design of bubble column reactors," Chemical Engineering Science, vol. 56, pp. 5893-5933, 2001.

[30] J. B. Joshi, V. S. Vitankar, A. A. Kulkarni, M. T. Dhotre, and K. Ekambara, "Coherent flow structures in bubble column reactors," Chemical Engineering Science, vol. 57, pp. 3157-3183, 2002.

[31] S. La1'n, D. Bröder, M. Sommerfeld, and M. F. Göz, "Modelling hydrodynamics and turbulence in a bubble column using the Euler-Lagrange procedure," International Journal of Multiphase Flow, vol. 28, pp. 1381-1407, 2002.

[32] A. Sokolichin, G. Eigenberger, and A. Lapin, "Simulation of buoyancy driven bubbly flow: Established simplifications and open questions," American Institute of Chemical Engineers Journal, vol. 50, pp. 24-45, 2004.

[33] D. Law, F. Battaglia, and T. Heindel, "Numerical simulations of gas-liquid flow dynamics in bubble columns," in Proceedings of 2006 ASME International Mechanical Engineering Congress and Exposition, Chicago, Illinois, USA, 2006, pp. 593-600.

[34] M. Rampure, V. Buwa, and V. Ranade, "Modelling of gas-liquid/gas-liquid-solid flows in bubble columns: Experiments and CFD simulations," The Canadian Journal of Chemical Engineering, vol. 81, no. 3-4, pp. $692-$ 706, 2003.

[35] A. F. Studely, "Numerical Modeling of Air-Water Flows in Bubble Columns and Airlift Reactors," Master's Thesis), Virginia Polytechnic Institute and State University, Blacksburg, Virginia, 2010.

[36] M. W. Abdulrahman, "CFD simulations of direct contact volumetric heat transfer coefficient in a slurry bubble column at a high gas temperature of a helium-water-alumina system," Applied Thermal Engineering, vol. 99, pp. 224-234, 2016.

[37] M. W. Abdulrahman, "CFD Analysis of Temperature Distributions in a Slurry Bubble Column with Direct Contact Heat Transfer," in proceedings of the 3rd International Conference on Fluid Flow, Heat and Mass Transfer (FFHMT'16), Ottawa, ON, Canada, 2016.

[38] ANSYS, ANSYS FLUENT Theory Guide. Release 14.5. ANSYS, Inc, 2012.

[39] A. Bejan, Convection heat transfer ( $3^{\text {rd }}$ ed.). John Wiley \& sons, Inc., 2004.

[40] G. K. Batchelor, (1967), An introduction to fluid dynamics. Cambridge University Press, Cambridge, England, 1967.

[41] M. M. Sarah, S. V. Vivek, and O. F. Rodney, "CFD predictions for flow-regime transitions in bubble columns," American Institute of Chemical Engineers Journal, vol. 51, no. 7, pp. 1897-1923, 2005.

[42] M. Rafique, P. Chen, P., and M. P. Duduković, "Computational modeling of gas-liquid flow in bubble columns," Reviews in Chemical Engineering, vol. 20, no. 3-4, pp. 225-375, 2004.

[43] A. Shaikh, and M. H. Al-Dahhan, "A review on flow regime transition in bubble columns," International Journal of Chemical Reactor Engineering, vol. 5, Review R1, 2007.

[44] A. Sokolichin, and G. Eigenberger, "Applicability of the standard $k-\varepsilon$ turbulence model to the dynamic simulation of bubble columns: Part I. Detailed numerical simulations," Chemical Engineering Science, vol. 54, pp. 2273-2284, 1999. 